\title{
Anesthetic management of modified electroconvulsive therapy for a patient with coronary aneurysms: a case report
}

\author{
Riho Nakayama, Takuya Yoshida* (D), Norihiko Obata and Satoshi Mizobuchi
}

\begin{abstract}
Background: Modified electroconvulsive therapy (m-ECT) is utilized worldwide as an effective treatment for drugresistant psychiatric disorders. However, during $\mathrm{m}-\mathrm{ECT}$, treatment of hypotension and hypertension in response to rapid hemodynamic changes is required. We used noninvasive continuous blood pressure monitoring system for continuous hemodynamic measurement during m-ECT.
\end{abstract}

Case presentation: The patient was a 77-year-old man with depression complicated by coronary artery aneurysms (CAAs). We managed general anesthesia during $\mathrm{m}$-ECT by using the ClearSight ${ }^{\mathrm{TM}}$ system (Edwards Lifesciences Corp, Irvine, CA, USA) for hemodynamic measurement. As a result, we performed a total of $10 \mathrm{~m}$-ECTs. No rupture of CAAs or myocardial ischemia occurred and depressive symptoms improved.

Conclusion: We successfully managed the anesthesia in m-ECT for a depressed patient with CAAs without complications by using the ClearSight ${ }^{\mathrm{TM}}$ system, which was used for the effective management of circulatory fluctuations.

Keywords: Modified electroconvulsive therapy, Coronary artery aneurysm, Anesthetic management, ClearSight ${ }^{\mathrm{TM}}$ system

\section{Background}

Modified electroconvulsive therapy (m-ECT) is a biological treatment procedure involving a brief application of electrical stimulation to produce a generalized seizure [1]. During m-ECT, rapid changes in heart rate (HR) and blood pressure (BP) are reported to occur, so sufficient attention is required to manage fluctuations in circulatory dynamics [1].

We report a case of anesthetic management of m-ECT for a depressed patient with coronary artery aneurysms (CAAs) by using a noninvasive continuous blood pressure monitoring system (ClearSight ${ }^{\mathrm{tw}}$ system, Edwards Lifesciences Corp, Irvine, CA, USA), which makes possible a non-invasive, prompt response to changes of the circulatory dynamics.

* Correspondence: takuyayoshida47@gmail.com

Department of Anesthesiology, Kobe University Hospital, 7-5-2 Kusunoki-cho, Chuo-ku, Kobe city, Hyogo 650-0017, Japan

\section{Case presentation}

A 77-year-old man, $55 \mathrm{~kg}$ in weight and $165 \mathrm{~cm}$ in height, was scheduled to undergo m-ECT, due to a decreasing efficacy of drug treatment for depression over 9 years.

Seven years earlier, coronary computed tomography (CT) showed two CAAs with diameters of $7 \times 8 \mathrm{~mm}$ and $6 \times 11 \mathrm{~mm}$ at the distal first diagonal branch of the left coronary artery and right ventricular fistula formation (Fig. 1). The diameter of CAAs had no changes during the follow-up observation for 7 years. In adenosine myocardial load scintigraphy as a preoperative examination, neither myocardial ischemia nor infarction was detected. We surmised that the infarct range of the heart would be limited even if a thrombus was formed because the CAAs were located at the distal side of the left first diagonal branch. For that reason, we decided to prioritize $\mathrm{m}$-ECT for depression rather than treatment for the CAAs.

Upon entering the operation room for the first mECT, the patient exhibited noninvasive blood pressure 


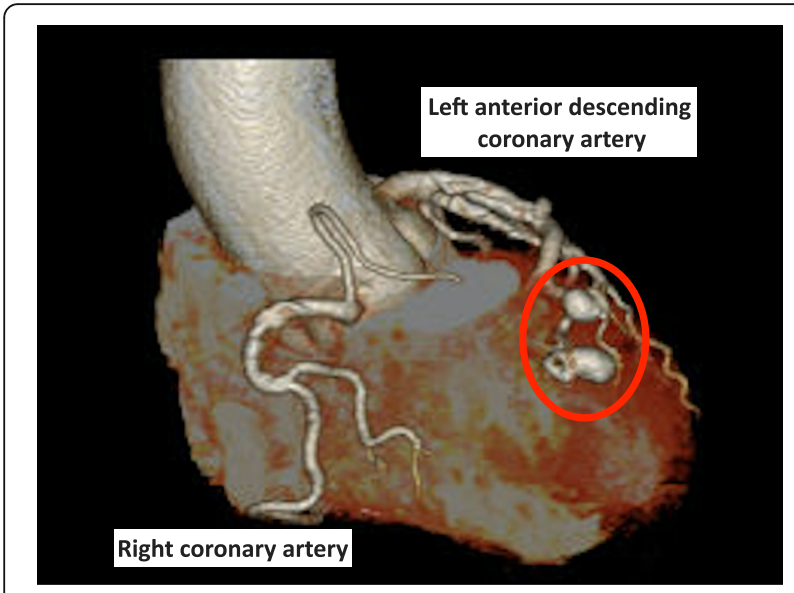

Fig. 1 Preoperative coronary 3D-CT: Two coronary artery aneurysms are recognized in the periphery of the left anterior descending branch (red circle)

(NIBP) of $124 / 79 \mathrm{mmHg}$, and the BP on the ClearSight ${ }^{\mathrm{m}}$ system was 132/74 $\mathrm{mmHg}$ (Fig. 2a). For setting the ClearSight $^{\text {tw }}$ system, we measured NIBP five times and confirmed that there was not much difference between NIBP and BP on the ClearSight ${ }^{\mathrm{tm}}$ system, and blood pressure was measured by this system throughout the procedure. General anesthesia was induced with propofol $1 \mathrm{mg} \mathrm{kg}{ }^{-1}$, and after he lost consciousness, rocuronium $0.35 \mathrm{mg} \mathrm{kg}^{-1}$ was administered. Nine minutes after rocuronium administration, the psychiatrist performed electrical stimulation. As soon as the seizure started, HR increased from 83 beats $\mathrm{min}^{-1}$ to 102 beats $\mathrm{min}^{-1}$, and BP increased from 101/59 $\mathrm{mmHg}$ to $143 / 85 \mathrm{mmHg}$. The seizure duration was $51 \mathrm{~s}$ on the electroencephalogram. When the seizure stopped, the BP rapidly decreased to $120 / 75 \mathrm{mmHg}$ without the use of any antihypertensive agent. After completing the seizure, sugammadex sodium $2 \mathrm{mg} \mathrm{kg}^{-1}$ was administered. When the patient regained consciousness, the BP was 112/71 mmHg. Neither asynergy nor pericardial effusion was detected by transthoracic echocardiography.

At the second m-ECT performed 4 days after the first procedure, when entering the operation room, NIBP was $144 / 111 \mathrm{mmHg}$, and the BP was $152 / 89 \mathrm{mmHg}$ (Fig. 2b). General anesthesia was performed by referring to the first $\mathrm{m}$-ECT. As soon as the seizure began after electrical stimulation, the BP increased from 155/93 $\mathrm{mmHg}$ to $186 /$ $105 \mathrm{mmHg}$. Therefore, nicardipine $0.01 \mathrm{mg} \mathrm{kg}^{-1}$ was administered, and BP decreased to $155 / 89 \mathrm{mmHg}$ immediately. After completing the seizure, the BP was 164/92 $\mathrm{mmHg}$. The seizure duration was $50 \mathrm{~s}$ on the electroencephalogram. We confirmed that there was no asynergy or pericardial effusion in the transthoracic echocardiography when he regained consciousness.
Both m-ECTs increased HR and BP. However, no decrease in HR or BP due to parasympathetic nervous stimulation or asystole was recognized. With reference to the first and second m-ECTs, we administered nicardipine hydrochloride prophylactically prior to the start of electrical stimulation every time after the third procedure. We performed a total of $10 \mathrm{~m}$-ECTs, and the maximum NIBP in the all m-ECT procedures was 171/ $99 \mathrm{mmHg}$.

\section{Discussion}

We present a case of successful anesthetic management in m-ECT for a patient with CAAs through prompt responses to changes in circulatory dynamics. As far as we know, this is the first report of $\mathrm{m}$-ECT for a patient with CAA.

In most cases, CAA is asymptomatic, but the slow flow of blood on the irregular internal surface of the aneurysm wall predisposes to the formation of thrombi with subsequent embolization, resulting in myocardial ischemia and infarction and sudden death [2]. We found some reports of CAA rupture [3, 4], and there is also a report that hypertension triggered CAA rupture [5]. Therefore, we needed to control BP closely in m-ECT and decided to target systolic blood pressure below 180 mmHg.

It is known that rapid fluctuations in circulatory dynamics occur during m-ECT [1]. We have to be careful because, before or after the HR and BP increase due to sympathetic nerve stimulation accompanying the electrical stimulation, sometimes a parasympathetic response dominates, and there have been some case reports of bradycardia and $10 \mathrm{~s}$ of asystole [6,7]. There have also been reports of cases in which asystole has occurred almost simultaneously with electrical stimulation [6]. Therefore, we thought that strict hemodynamic monitoring during $\mathrm{m}$-ECT was needed. Because this case was complicated by CAAs, we decided to use the ClearSight ${ }^{\mathrm{tm}}$ system to see the hemodynamic change clearly during $\mathrm{m}$-ECT, with the goal of not raising blood pressure excessively, to prevent CAA rupture.

The ClearSight ${ }^{\text {tix }}$ system is a hemodynamic monitoring system that allows for real-time non-invasive BP measurements. Juri et al. reported the efficacy of the ClearSight $^{\text {Tw }}$ system during cesarean section with accurate BP management [8]. Sumiyoshi et al. also reported that there is a significant relationship between mean arterial pressure and mean arterial pressure of the ClearSight ${ }^{\mathrm{m}}$ system in patients with abdominal aortic aneurysm surgery [9]. Earle et al. reported that the ClearSight ${ }^{\text {Th }}$ system was useful in m-ECT for a patient with abdominal aortic aneurysms [10]. In Earle's report, the waveform of the ClearSight $^{\mathrm{mu}}$ system disappeared for approximately $20 \mathrm{~s}$ due to electrical stimulation in m-ECT. However, when 


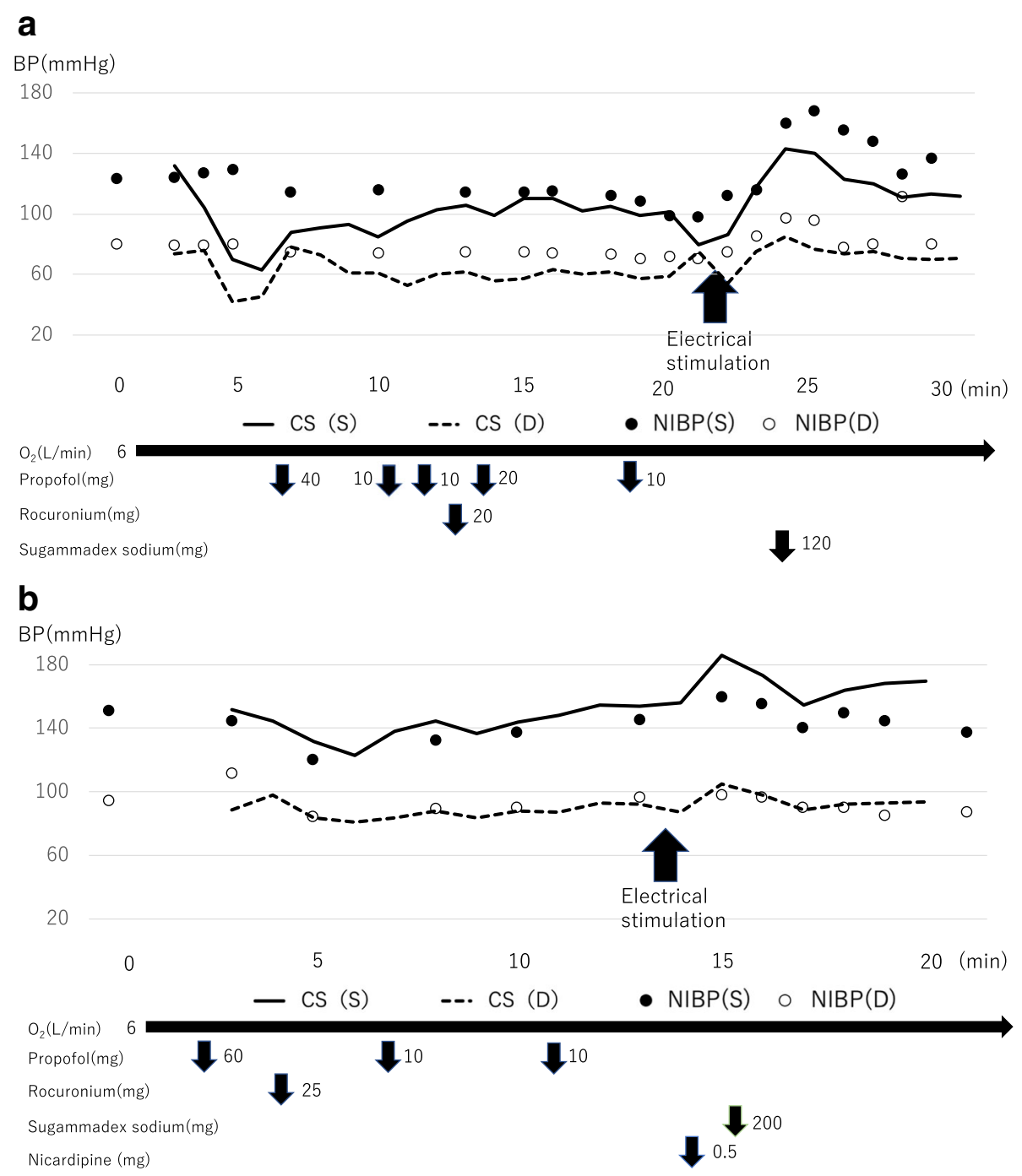

Fig. 2 a The anesthetic chart of first $m-E C T$. $\mathbf{b}$ The anesthetic chart of second $m-E C T$. There was not much difference between NIBP and BP on the ClearSight ${ }^{\mathrm{TM}}$ system in both charts. CS (S): systolic blood pressure of the ClearSight ${ }^{\mathrm{TM}}$ system. CS (D): diastolic blood pressure of the ClearSight ${ }^{\mathrm{TM}}$ system. NIBP (S): systolic blood pressure of NIBP. NIBP (D): diastolic blood pressure of NIBP

we used the ClearSight ${ }^{\text {tim }}$ system, the arterial pressure waveform did not disappear during $\mathrm{m}-\mathrm{ECT}$, so we could monitor BP continuously and manage patient safety.

The first and second m-ECTs with the ClearSight ${ }^{\mathrm{tm}}$ system showed that electrical stimulation increased HR and BP but did not cause asystole and that prophylactic nicardipine administration did not cause excessive BP reduction.

We performed a total of $10 \mathrm{~m}$-ECTs. No rupture of CAAs or myocardial ischemia occurred, and depressive symptoms improved through this series of m-ECTs.

In conclusion, we successfully managed the anesthesia in m-ECT for a depressed patient with CAAs by using the ClearSight ${ }^{\mathrm{Tm}}$ system, which was used for the effective management of BP fluctuations during $\mathrm{m}-\mathrm{ECT}$.
Abbreviations

BIS: Bispectral index; BP: Blood pressure; CAA: Coronary artery aneurysm; $C T$ : Computed tomography; HR: Heart rate; m-ECT: Modified electroconvulsive therapy; NIBPq: Noninvasive blood pressure

\section{Acknowledgements}

Not applicable

Authors' contributions

RN collected data and drafted the manuscript. TY and NO revised the manuscript for important intellectual content. SM supervised the study. All authors have read and approved the final version to be published.

\section{Funding}

The authors declare that they have no funding.

\section{Availability of data and materials}

The data in this case report are available from the corresponding author on reasonable request. 


\section{Ethics approval and consent to participate}

This case report was approved by the institutional ethics committee (Ethics Committee, Kobe University Graduate School of Medicine, Japan).

Ethics approval is waived because this manuscript is a case report.

\section{Consent for publication}

Written informed consent was obtained from the patient for publication of this case report.

\section{Competing interests}

The authors declare that they have no competing interests.

Received: 12 September 2019 Accepted: 12 November 2019

Published online: 22 November 2019

\section{References}

1. Kerner N, Prudic J. Current electroconvulsive therapy practice and research in the geriatric population. Neuropsychiatry (London). 2014;4(1):33-54

2. Abou Sherif S, Ozden Tok O, Taskoylu O, Goktekin O, Kilic ID. Coronary artery aneurysms: a review of the epidemiology, pathophysiology, diagnosis, and treatment. Front Cardiovasc Med. 2017:4:24.

3. Kondo T, Takahashi M, Nakagawa K, Kuse A, Morichika M, Sakurada M, et al. Rupture of massive coronary artery aneurysm resulting in cardiac tamponade. Leg Med (Tokyo). 2015;17(5):388-90.

4. Kimura S, Miyamoto K, Ueno Y. Cardiac tamponade due to spontaneous rupture of large coronary artery aneurysm. Asian Cardiovasc Thorac Ann. 2006;14(5):422-4

5. Iwasawa Y, Kitamura Y, Higuma K, Ono F, Imoto K, Kimura K. Cardiac tamponade due to rupture of coronary artery fistulas with a giant aneurysm containing a free floating ball thrombus: a case report. J Cardiol. 2007;50(1):71-6.

6. Marnie R, Geoffery L. Asystole during successive electroconvulsive therapy sessions: a report of two cases. Journal of Clinical Anesthesia. 2004:16:210-3.

7. Ethan $\mathrm{O}$, Matthew $\mathrm{F}$, Justin P. Vagally mediated postictal asystole during electroconvulsive therapy. Journal of ECT. 2018;34:1.

8. Juri T, Suehiro K, Kimura A, Mukai A, Tanaka K, Yamada T, et al. Impact of non-invasive continuous blood pressure monitoring on maternal hypotension during cesarean delivery: a randomized-controlled study. J Anesth. 2018:32(6):822-30.

9. Sumiyoshi M, Maeda T, Miyazaki E, Hotta N, Sato H, Hamaguchi E, et al. Accuracy of the ClearSight system in patients undergoing abdominal aortic aneurysm surgery. J Anesth. 2019;33(3):364-71.

10. Earle R, Vaghadia H, Sawka A. Novel use of the Nexfin HD monitor for hemodynamic management during electroconvulsive therapy in a patient with an unrepaired abdominal aortic aneurysm. Can J Anaesth. 2015;62(6):674-5

\section{Publisher's Note}

Springer Nature remains neutral with regard to jurisdictional claims in published maps and institutional affiliations.

\section{Submit your manuscript to a SpringerOpen ${ }^{\circ}$ journal and benefit from:}

- Convenient online submission

- Rigorous peer review

- Open access: articles freely available online

- High visibility within the field

- Retaining the copyright to your article

Submit your next manuscript at $\boldsymbol{\nabla}$ springeropen.com 